University of Nebraska - Lincoln

DigitalCommons@University of Nebraska - Lincoln

Faculty Papers and Publications in Animal

Science

Animal Science Department

2019

\title{
The heritability of pampiniform plexus vessel size and varicocoele in boars
}

Tasha R. Gruhot

University of Nebraska - Lincoln, trgruhot@gmail.com

Lea A. Rempel

USDA, Agricultural Research Service, lea.rempel@usda.gov

Matthew L. Spangler

University of Nebraska - Lincoln, mspangler2@unl.edu

Stephen D. Kachman

University of Nebraska-Lincoln, steve.kachman@unl.edu

Benny E. Mote

University of Nebraska-Lincoln, benny.mote@unl.edu

Follow this and additional works at: https://digitalcommons.unl.edu/animalscifacpub

Part of the Genetics and Genomics Commons, and the Meat Science Commons

Gruhot, Tasha R.; Rempel, Lea A.; Spangler, Matthew L.; Kachman, Stephen D.; and Mote, Benny E., "The heritability of pampiniform plexus vessel size and varicocoele in boars" (2019). Faculty Papers and Publications in Animal Science. 1072.

https://digitalcommons.unl.edu/animalscifacpub/1072

This Article is brought to you for free and open access by the Animal Science Department at DigitalCommons@University of Nebraska - Lincoln. It has been accepted for inclusion in Faculty Papers and Publications in Animal Science by an authorized administrator of DigitalCommons@University of Nebraska Lincoln. 


\title{
The heritability of pampiniform plexus vessel size and varicocoele in boars
}

\author{
Tasha R. Gruhot ${ }^{1}$ (D) | Lea A. Rempel ${ }^{2}$ ｜ Matthew L. Spangler ${ }^{1}$ ～Stephen D. Kachman ${ }^{3}$ | \\ Benny E. Mote ${ }^{1}$
}

${ }^{1}$ Department of Animal Science, University of Nebraska-Lincoln, Lincoln, Nebraska

${ }^{2}$ United States Department of Agriculture, Agricultural Research Service, United States Meat Animal Research Center, Clay Center, Nebraska

${ }^{3}$ Department of Statistics, University of Nebraska-Lincoln, Lincoln, Nebraska

\section{Correspondence}

Tasha R. Gruhot, Department of Animal Science, University of Nebraska-Lincoln, Lincoln, NE.

Email: trgruhot@gmail.com

\section{Contents}

Ultrasonography was used to capture a coronal-sagittal image of the veins of the pampiniform plexus (PP) and the testicular artery of 327 maternal-line boars at approximately 6 months of age at the University of Nebraska-Lincoln. Varicocoele was diagnosed by two methods. Method 1 diagnosed varicocoele when the average vessel area on one side of the scrotum was 1.5 times larger than the average vessel area on the other side of the scrotum. Method 2 diagnosed varicocoele when the average vessel area on one side of the scrotum of a boar was 1.5 times larger than the average vessel on the same side of the scrotum of the boar's cohorts (same population and year). Varicocoele was diagnosed in $23.17 \%$ and $15.1 \%$ of boars measured using method 1 and method 2, respectively. Ultrasonography showed to be an effective means to measure PP vessel size in boars and may even allow for earlier detection of varicocoele than by using palpation. Animal models were employed to estimate the heritability for: average area of right PP vessels (0.52), average area of the left PP vessels (0.46), varicocoele presence using method $1(0.26)$ and varicocoele presence using method 2 (0.25). These heritability estimates suggest that vessel size and varicocoele could be selected against in breeding programmes to potentially improve boar semen quality.

\section{KEYWORDS}

heritability, pampiniform plexus, swine, varicocoele

\section{1 | INTRODUCTION}

Varicocoele is an abnormality of the pampiniform plexus (PP), where vascular lesions and/or tortuous dilated veins occur. The presence of varicocoele has known associations with male infertility (Jarow, 2001). Countercurrent heat exchange of the PP is hindered when varicocoele is present due to improper cooling of abdominal blood entering the testicle with varicocoele. The abnormally warm blood causes the testicle with varicocoele to have a higher than normal

Mention of trade name proprietary product or specified equipment does not constitute a guarantee or warranty by the USDA and does not imply approval to the exclusion of other products that may be suitable. Research is supported by USDA-ARS, CRIS project no. 3040-31000-095. USDA is an equal opportunity provider and employer. temperature, which can lead to impaired testicular function (Hsiung, Nieva, \& Clavert, 1991).

Varicocoeles are the most common physical abnormality reported in human men with reduced semen quality parameters and fertility issues (Sigman \& Howards, 1998; Sigman \& Jarow, 1997). Reproductive tracts of boars that were reported to have poor semen quality for at least 5 weeks prior to culling were examined in a study conducted by Úbeda et al. (2014). Twenty-two per cent of these boars were reported to have varicocoeles (Úbeda et al., 2014). In a group of boars examined for testicle abnormalities, $23.4 \%$ of the adult boars were diagnosed by palpation with varicocoele (KleveFeld, Riesenbeck, Beyerbach, \& Waberski, 2015). A significant effect 
on sperm membrane integrity, as well as a significant increase in sperm morphology abnormalities, was reported in the boars affected by varicocoele (Kleve-Feld et al., 2015).

To the authors' knowledge, the heritability of PP vessel size, as well as the presence of varicocoele, has not previously been estimated in any species. Incidence of varicocoele in men that have firstdegree relatives with varicocoele has been examined to evaluate the familial risk. When compared to the control population, a significant threefold to eightfold increase in varicocoele was reported in the group of men with first-degree relatives affected by varicocoele (Gökçe et al., 2010; Raman, Walmsley, \& Goldstein, 2005). This previous research indicates a genetic component in the control of varicocoele in men. The degree to which genetics control varicocoele in swine is unknown. Therefore, the objective of this study was to estimate preliminary heritability estimates for PP vessel size and varicocoele presence in boars.

\section{2 | MATERIALS AND METHODS}

Research protocols and methods were approved by the University of Nebraska Institutional Animal Care and Use Committee.

\subsection{Boars utilized}

A total of 327 boars of approximately 6 months of age ( $=180$ days of age 15 days) were measured via ultrasonography for average PP vessel size at the University of Nebraska-Lincoln research farm and used in the analysis. Group 1, measured in 2016, consisted of 127 boars from 16 sires, with an average of 7.9 boars per sire. Group 2, measured in 2017, consisted of 112 sons from 11 of the previously measured boars (group 1) for an average of 10.2 boars per sire. Group 1 and group 2 were from the Nebraska Index Line, which is a composite of the breeds Landrace and Large White (Petry \& Johnson, 2004). The third group was measured in 2018 and contained 88 boars. Group 3 consisted of sons of full-sibling females to the boars measured in 2017, sired by 14 industry Yorkshire sires, for an average of 6.2 boars per sire. Boars in groups 1 and 2 had a known pedigree of four generations through both the dam and the sire. Boars in group 3 had a known four-generation pedigree through their dam, but only boar's sire was known on the sire side of the pedigree.

\section{2 | Pampiniform plexus vessel measurement and varicocoele diagnosis}

Ultrasonography was performed for each side of the scrotum by orientating the transducer towards the lower half of the testicle at approximately a $45^{\circ}$ angle. This technique captured a coronal-sagittal image of the testicular artery and the veins of the PP. An Ibex EVO ultrasound (E.I. Medical Imaging, Loveland, CO) with a $6.5 \mathrm{MHz}$ linear endorectal probe (L6E) was utilized. Bioquant image system (Bioquant Image Analysis Corp., Nashville, TN) was used to compile all images into a collage. Using the Bioquant image system, the area $\left(\mathrm{mm}^{2}\right)$ of 3 to 10 vessels of the PP was measured and the average area of right PP vessels (AAR) and of the left PP vessels (AAL), as well as the standard deviation for each PP, was derived.
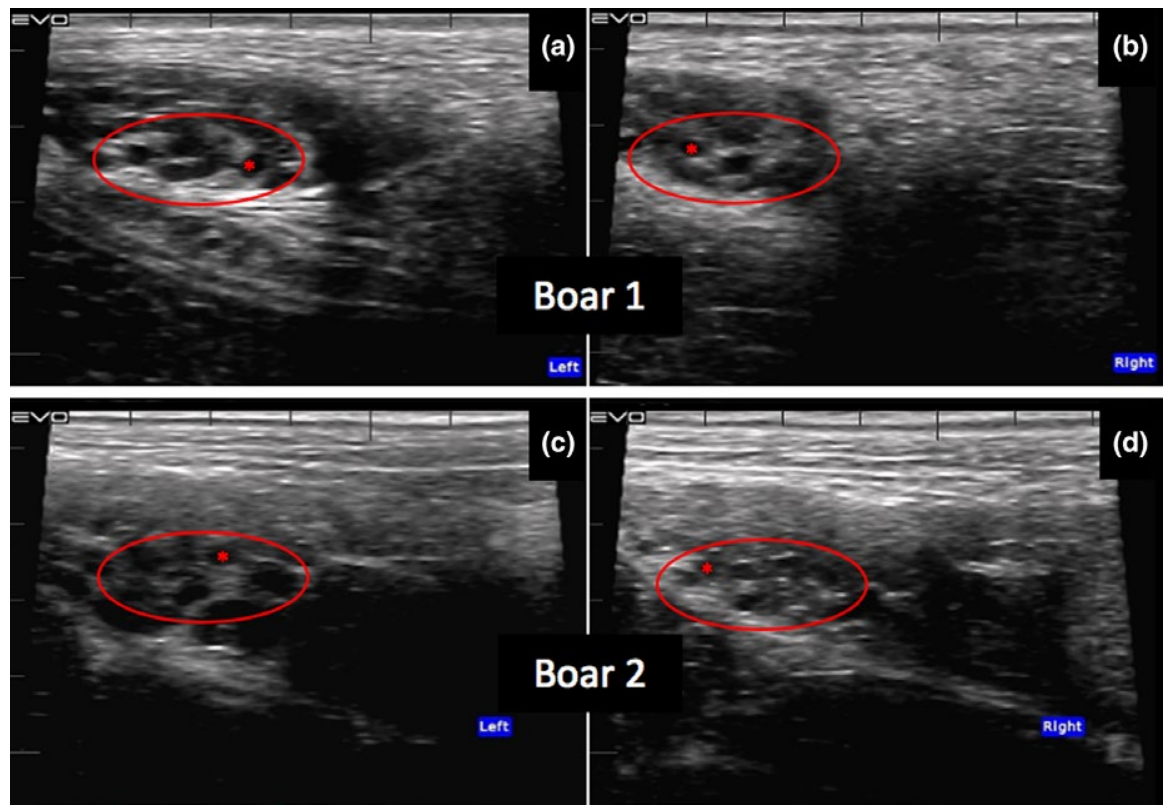

FIGURE 1 Ultrasound images of a boar without varicocoele (Boar 1) and a boar with varicocoele in the left pampiniform plexus (Boar 2). Red ovals on each ultrasound image indicate the cross section of the pampiniform plexus (PP) vessels. One representative vessel per image is identified with an asterisk $(*)$. Using the Bioquant image system, the area $\left(\mathrm{mm}^{2}\right)$ of 3 to 10 vessels of the PP was measured and the average area of right PP vessels (AAR) and of the left PP vessels (AAL) was derived. Panels a and $b$ represent the left and right PP vessel images for a boar, respectively. The left and right vessel ratios (AAL/AAR or AAR/AAL, respectively) of Boar 1 were $<1.5$; therefore, the boar was identified as non-varicocoele. Panels $c$ and $d$ are representative images from a boar (Boar 2) with varicocoele in the left plexus (AAL/AAR $>1.5)$ 
To assess the presence or absence of varicocoele, ratios of vessel size were utilized. A within-boar vessel ratio was estimated for each PP. The within-boar ratios were as follows: ( $A A L$ of boar $X$ / AAR of boar $X$ ) and (AAR of boar X/AAL of boar X), and if either ratio exceeded 1.5 , the boar was considered suspect varicocoele via method 1. Method 1 allowed for the identification of boars with unilateral varicocoele. Individual boars were also compared against their contemporaries and considered varicocoele if a ratio exceeded 1.5 via method 2 . The following ratios were utilized for method 2: (AAL of boar X/average AAL of the population) and (AAR of boar X/ average AAR of the population). Method 2 was performed in order to identify: (a) boars in which both PP vessel areas were enlarged and a difference within boar would not have been observed, suggesting bilateral varicocoele, and (b) boars that had a marginal difference (less than 1.5) between their own PP vessel areas, and however, when compared to their contemporaries, a difference $(>1.5)$ was identified. The presence or absence of varicocoele was treated as a binary trait. For each method, a boar suspected of varicocoele on either the left or right side was assigned a 1, otherwise they were assigned a 0 . Example ultrasound images of a boar with varicocoele and a boar without varicocoele, diagnosed via method 1, are provided in Figure 1.

\section{3 | Statistical analysis}

A paired $t$ test was used to test for a significant difference between $A A L$ and $A A R$ vessel size for all boars sampled. These analyses were conducted in $\mathrm{R}$ ( $\mathrm{R}$ Core \& Team, 2018).

A bivariate animal model was fitted using ASreml 3 (Gilmour et al., 2008) to estimate (co)variance components for AAL and AAR, as well as the genetic correlation, phenotypic correlation and narrow-sense heritabilities. Fixed effects included weight at time of measurement, year of measurement and line nested within year. Random effects included the additive genetic component and residual. The genetic correlation was estimated to be 1.0. As this results in a singular covariance matrix, the genetic correlation was fixed to 0.99 .

Univariate threshold animal models were utilized to estimate variance components for the presence of varicocoele for methods 1 and 2. The threshold model was fitted using a logit cumulative probability model, and contained the fixed effects of weight at time of measurement, year of measurement and line nested within year, with the random effect of animal. Heritabilities are reported on the underlying scale, utilizing the logistic distribution.

\section{3 | RESULTS}

\section{1 | Relationship between AAL and AAR}

The AAL and AAR were significantly different $(p<0.001)$, with AAL being an average of 1.18 times larger than AAR (Table 1). The estimate of phenotypic correlation between $A A L$ and AAR was $0.55 \pm 0.22$, and the estimate of genetic correlation was 1.0.
TAB LE 1 Average area of right pampiniform plexus vessels (AAR) and of the left pampiniform plexus vessels $(A A L)$ with their respective standard deviations $(S D)$

$\begin{array}{lll} & \text { Mean area }\left(\mathrm{mm}^{2}\right) & S D \\ \text { AAR } & 6.28^{*} & 2.90 \\ \text { AAL } & 7.39^{*} & 3.47\end{array}$

"Statistically different as determined from the paired $t$ test $(p<0.001)$

TAB LE 2 Percentage of boars determined to be suspect varicocoele using two methods of varicocoele diagnosis

\begin{tabular}{|c|c|}
\hline & Percentage \\
\hline$L / R^{a}$ & 18.89 \\
\hline$R / L^{b}$ & 4.28 \\
\hline L/Lpop ${ }^{c}$ & 9.66 \\
\hline R/Rpop ${ }^{d}$ & 9.92 \\
\hline Method $1^{\mathrm{e}}$ & 23.17 \\
\hline Method $2^{f}$ & 15.1 \\
\hline Method 2: bilateral ${ }^{\mathrm{g}}$ & 4.4 \\
\hline Method $1 \& 2$ overlap $^{h}$ & 4.7 \\
\hline
\end{tabular}

${ }^{a} L / R$ is the percentage of boars exceeding a 1.5 ratio of the average left pampiniform plexus vessel size (AAL) of boar X/average right pampiniform plexus vessel size (AAR) of boar $X .{ }^{b} R / L$ is the percentage of boars exceeding a 1.5 ratio of (AAR of boar X/AAL of boar X). ${ }^{\mathrm{C}} \mathrm{L} / \mathrm{Lpop}$ is the percentage of boars exceeding a 1.5 ratio of (AAL of boar X/average AAL of the population given year of measurement). ${ }^{d} R / R p o p$ is the percentage of boars exceeding a 1.5 ratio of (AAR of boar X/average AAR of the population given year of measurement). ${ }^{e}$ Summation of $L / R \& R / L$ (within-boar method) fSummation of L/Lpop and R/Rpop. Boars with bilateral varicocoele are only included once. ${ }^{\mathrm{g}} \mathrm{Per}$ cent of boars with bilateral varicocoele determined from L/Lpop and R/Rpop. ${ }^{h}$ Boars classified as suspect varicocoele under both methods of diagnosis.

\section{2 | Varicocoele presence}

Results for the presence of varicocoele are presented in Table 2. Varicocoele occurred more often in the left PP than the right PP utilizing method 1 . When the presence of both right side and left side varicocoeles was summed, $23.17 \%$ of the boar population showed varicocoele with method 1 . Method 2 permits varicocoele diagnosis on the left side, right side and/or bilaterally. Under method 2, left or right side varicocoele was diagnosed for approximately $10 \%$ of the population each, and approximately $4 \%$ of boars were determined to have bilateral varicocoele. When varicocoele was considered a binary trait regardless of diagnosis side, $15.1 \%$ of the population was considered suspect varicocoele under method 2, as bilateral boars are only counted once. Boars that were classified as suspect varicocoele using both methods consisted of $4.7 \%$ of the population.

\section{3 | Heritability estimates}

Heritability estimates for AAL and AAR are presented in Table 3. Both AAL and AAR were found to be highly heritable, $0.52 \pm 0.13$ 
and $0.46 \pm 0.13$, respectively. Heritability estimates for the presence of varicocoele are also presented in Table 3 , and were moderately heritable, method $1(0.26 \pm 0.03)$ and method $2(0.25 \pm 0.03)$.

\section{4 | DISCUSSION}

The genetic correlation of 1.0 between AAL and AAR implies that these are the same trait genetically. By selecting against large vessel size in one PP, the opposing PP would also be influenced. If selected against, special care should be taken that PP vessel size, especially on the right where varicocoele occurs less often, is not reduced to a point that could potentially hinder the countercurrent heat exchange of the PP.

The larger AAL compared to AAR was not unexpected and explained the higher incidence of varicocoele on the left side when utilizing the within-boar ratio. This scenario has previously been described in men with a higher reported predominance of varicocoele on the left side of the scrotum. This is thought to be caused by the long course of entry of the left testicular vein into the left renal vein (Sabanegh \& Agarwal, 2012). When men are diagnosed with varicocoele, it is either done with a subjective diagnosis via a physician through palpation or ultrasonographically (Jarow, 2001; Pryor, 2003). When palpation is used, diagnosis is based on how visible the vascular lesions are on a scale of highly visible and easy to palpate, to difficult to palpate and not visible, and vessel size has not been compared to any other person/group (Jarow, 2001). With ultrasound, varicocoele is diagnosed when the vein/testicular vein is greater than a threshold value (Pryor, 2003). The palpation method has previously been used to diagnose varicocoele in live boars by Kleve-Feld et al., (2015), where $23.4 \%$ of the boar population were considered suspect varicocoele. This estimate matches closely to the method 1 estimate in the current study of $23.17 \%$ of boars being considered suspect varicocoele. However, the $23.4 \%$ estimate was for adult boars in the Kleve-Feld et al. (2015) study, whereas in the

TAB LE 3 Heritability and standard error (SE) estimates for the average area of the right pampiniform plexus vessels (AAR), the average area of the left pampiniform plexus vessels (AAL) and the presence of varicocoele

\begin{tabular}{|ll|} 
& Heritability (SE) \\
\hline AAR & $0.52(0.13)$ \\
\hline AAL & $0.46(0.13)$ \\
\hline Within: Presence & $0.26(0.03)$ \\
\hline Population: $^{a}$ Presence $^{\mathrm{b}}$ & $0.25(0.03)$ \\
\hline
\end{tabular}

apresence of varicocoele determined from the following ratios: (AAL of boar X/AAR of boar X) or (AAR of boar X/AAL of boar). When the ratio exceeded a 1.5 threshold, varicocoele was considered suspect. ${ }^{\mathrm{b}}$ Presence of varicocoele determined from the following ratios: (AAR of boar $X$ /average $A A R$ of the population given year of measurement) and (AAL of boar X/average AAL of the population given year of measurement). When the ratio exceeded a 1.5 threshold, varicocoele was considered suspect. This includes boars with unilateral varicocoele and bilateral varicocoele. current study young boars were measured (approximately 6 months of age). Kleve-Feld et al., (2015) also reported prevalence of varicocoele in young boars (7-12 months of age) at $7.2 \%$, which is lower than what the current study estimated. This could indicate that the use of ultrasound to diagnosis varicocoele allowed for earlier diagnosis than palpation would allow. These results also suggest that regardless of breed, the prevalence of varicocoele in the boar population remains approximately the same. In the study conducted by Kleve-Feld et al., (2015), the terminal Pietrain breed was used to estimate varicocoele occurrence compared to the current study, which utilized only maternal-based lines. The incidence of varicocoele in boar populations is slightly higher than what has been reported in human populations at approximately 15\% (Gökçe et al., 2010; Gorelick \& Goldstein, 1993; Raman et al., 2005).

When using method 2 , approximately $15 \%$ of boars were found to be suspect varicocoele, which is lower than what was previously reported in boars but similar to what has been found in humans (Gökçe et al., 2010; Gorelick \& Goldstein, 1993; Kleve-Feld et al., 2015; Raman et al., 2005). Method 2 allows boars with bilateral varicocoele to be captured, unlike method 1 that can only diagnosis varicocoele unilaterally. The diagnosis of varicocoele in boars is still a novel practice, which is why two methods were utilized in this study. More research needs to be conducted analysing semen quality of boars diagnosed with varicocoele under the different methods to determine which method does a more precise job of identifying boars with varicocoele that impacts semen quality.

Pampiniform plexus vessel size was found to be highly heritable. To the authors' knowledge, no other studies have reported heritability estimates for PP vessel size in any species. However, a study conducted in humans which assessed the heritability of the central retinal artery and the central retinal vein reported estimates of 0.70 and 0.83, respectively (Taarnhøj et al., 2006). Though the vessel size heritability estimates reported by Taarnhøj et al. (2006) are higher than what is reported in the current study, this supports the finding of vessel size being a highly heritable trait.

The current study found the presence of varicocoele to be moderately heritable. Previous research in relation to varicocoele heritability in all species is very limited. In human studies, a significant increase in the presence of varicocoele occurred in first-degree relatives in men with a known varicocoele compared to a control population. Among the first-degree relatives of men with known varicocoele, 36.2\% (Gökçe et al., 2010), 45.5\% (Mokhtari, Pourreza, Falahatkar, Kamran, \& Jamali, 2008) and 56.6\% (Raman et al., 2005) have been reported with palpable varicocoele. This indicates a genetic component to the presence of varicocoele, which is in agreement with the current study.

The presence of varicocoele in boars as well as humans has been shown to negatively influence semen quality (Kamal, Jarvi, \& Zini, 2001; Kleve-Feld et al., 2015; Pasqualotto et al., 2005). As the results of the current study indicate that varicocoele presence is a heritable trait, this suggests an opportunity to select against varicocoele in boars to potentially improve semen quality. When considering that varicocoele effects roughly $20 \%$ of boars across breeds, as 
determined by the current study and Kleve-Feld et al., (2015), the presence of varicocoele could be unknowingly having substantial negative effects on semen quality industrywide.

\section{5 | CONCLUSION}

The use of ultrasound to diagnosis varicocoele in boars proved an effective method and potentially allows for diagnosis of varicocoele prior to what could be diagnosed via palpation. Pampiniform plexus vessel size and the presence of varicocoele were found to be moderately to highly heritable traits indicating that varicocoele could be selected against in the boar population to reduce its incidence and potentially improve semen quality. More research is needed to determine how semen quality is influenced by varicocoele under the two methods of diagnosis described in this study. Future studies should also investigate whether a difference exists in arterial/venous blood flow in boars with and without varicocoele and the testicular temperature relationship.

\section{CONFLICT OF INTEREST}

None of the authors have any conflict of interest to declare.

\section{AUTHOR CONTRIBUTIONS}

Tasha Gruhot assisted in ultra-sounding the boars, conducted the statistical analysis and drafted the manuscript. Benny Mote assisted in ultra-sounding the boars, designing study and revising the manuscript. Lea Rempel assisted in ultra-sounding the boars, designing study, statistical analysis and revising the manuscript. Matthew Spangler and Stephen Kachman assisted in the statistical analysis and revising the manuscript.

\section{ORCID}

Tasha R. Gruhot (iD http://orcid.org/0000-0002-3384-7449

\section{REFERENCES}

Gilmour, A. R., Gogel, B. J., Cullis, B. R., Thompson, R., Butler, D., Cherry, M., ... Haskard, K. (2008). Asreml user guide release 3.0. Hemel Hempstead, UK: VSN Int. Ltd.

Gökçe, A., Davarci, M., Yalçinkaya, F., Güven, E., Kaya, Y., Helvaci, M., \& Balbay, M. (2010). Hereditary behavior of varicocoele. Journal of Andrology, 31, 288-290. https://doi.org/10.2164/jandrol.109.008698

Gorelick, J. I., \& Goldstein, M. (1993). Loss of fertility in men with varicocoele. Fertility and Sterility, 59, 613-616.

Hsiung, R., Nieva, H., \& Clavert, A. (1991). Scrotal hyperthermia and varicocoele. Advances in Experimental Medicine and Biology, 286, 241-244.
Jarow, J. P. (2001). Effects of varicocoele on male fertility. Human Reproduction Update, 7, 59-64.

Kamal, K. M., Jarvi, K., \& Zini, A. (2001). Microsurgical varicocoelectomy in the era of assisted reproductive technology: Influence of initial semen quality on pregnancy rates. Fertility and Sterility, 75, 10131016. https://doi.org/10.1016/S0015-0282(01)01698-3

Kleve-Feld, M., Riesenbeck, A., Beyerbach, M., \& Waberski, D. (2015). varicocoele testis in Piétrain boars and its effect on sperm quality. Reproduction in Domestic Animals, 50, 50-51.

Mokhtari, G., Pourreza, F., Falahatkar, S., Kamran, A. N., \& Jamali, M. (2008). Comparison of prevalence of varicocoele in firstdegree relatives of patients with varicocoele and male kidney donors. Urology, 71, 666-668. https://doi.org/10.1016/j. urology.2007.11.116

Pasqualotto, F. F., Lucon, A. M., De Góes, P. M., Sobreiro, B. P., Hallak, J., Pasqualotto, E. B., \& Arap, S. (2005). Semen profile, testicular volume, and hormonal levels in infertile patients with varicocoeles compared with fertile men with and without varicoceles. Fertility and Sterility, 83, 74-77. https://doi.org/10.1016/j. fertnstert.2004.06.047

Petry, D., \& Johnson, R. K. (2004). Responses to 19 generations of litter size selection in the nebraska index line. I. Reproductive responses estimated in pure line and crossbred litters 1. Journal of Animal Science, 82, 1000-1006. https://doi.org/10.2527/2004.8241000x

Pryor, J. (2003). Role of urologists in evaluating male infertility, with emphasis on ultrasound. Ultrasound in Medicine \& Biology, 29, 40. https:// doi.org/10.1016/S0301-5629(03)00207-2

R Core Team. (2018). A language and environment for statistical computing. Vienna, Austria: R Foundation for Statistical Computing.

Raman, J. D., Walmsley, K., \& Goldstein, M. (2005). Inheritance of varicoceles. Urology, 65, 1186-1189. https://doi.org/10.1016/j. urology.2004.12.057

Sabanegh, E., \& Agarwal, A. (2012). Male infertility. In A. J. Wein, L. R. Kavoussi, A. C. Novick, \& A. W. Partin, (Eds.), Campbell-walsh urology male infertility, 10th ed. Philadelphia, PA: Saunders.

Sigman, M., \& Howards, S. (1998). Campbell's urology. Philadelphia, PA: Male infertility.

Sigman, M., \& Jarow, J. (1997). Ipsilateral testicular hypotrophy is associated with decreased sperm counts in infertile men with varicocoeles. Journal of Urology, 158, 605-607. https://doi.org/10.1016/ S0022-5347(01)64567-1

Taarnhøj, N. C. B., Larsen, M., Sander, B., Kyvik, K. O., Kessel, L., Hougaard, J. L., \& Sørensen, T. I. A. (2006). Heritability of retinal vessel diameters and blood pressure: A twin study. Investigative Ophthalmology \& Visual Science, 47, 3539-3544. https://doi. org/10.1167/iovs.05-1372

Úbeda, J., Ausejo, R., Dahmani, Y., Falceto, M., Moreno, B., \& Yeregui, J. (2014). Post mortem anatomic study of boar testicles from Spanish Al centers. Proc. 23rd IPVS Congress. Cancun, Mexico. 188.

How to cite this article: Gruhot TR, Rempel LA, Spangler ML, Kachman SD, Mote BE. The heritability of pampiniform plexus vessel size and varicocoele in boars. Reprod Dom Anim. 2019;54:270-274. https://doi.org/10.1111/rda.13350 